\title{
Thermochemical Hydrogen Storage via the Reversible Reduction and Oxidation of Metal Oxides
}

\section{Journal Article}

Author(s):

Brinkman, L.; Bulfin, Brendan; Steinfeld, Aldo (D)

Publication date:

2021-11-18

Permanent link:

https://doi.org/10.3929/ethz-b-000516044

\section{Rights / license:}

Creative Commons Attribution-NonCommercial-NoDerivatives 4.0 International

Originally published in:

Energy \& Fuels 35(22), https://doi.org/10.1021/acs.energyfuels.1c02615

\section{Funding acknowledgement:}

823802 - Solar Facilities for the European Research Area - Third Phase (EC) 


\title{
Thermochemical Hydrogen Storage via the Reversible Reduction and Oxidation of Metal Oxides
}

\author{
L. Brinkman, B. Bulfin,* and A. Steinfeld
}

Cite This: Energy Fuels 2021, 35, 18756-18767

Read Online

ABSTRACT: In this work, we perform a technical analysis of a cyclic reduction and oxidation process of metal oxides applied as a hydrogen storage route. Hydrogen is used to reduce a metal oxide and form steam, and regenerated by oxidizing the reduced metal oxide with steam. The reduced metal acts as the solid storage medium, which could be transported or used for stationary applications. Suitable metal oxides were screened according to the following performance indicators: specific energy demand (enthalpy change of reaction), thermodynamic conversion extents, specific storage density, resistance to sintering (melting point), and material cost. Iron oxide was then selected as the most promising candidate. A thermodynamic model was developed to determine favorable process temperatures of $>400{ }^{\circ} \mathrm{C}$ for the hydrogen storage step and $100-500{ }^{\circ} \mathrm{C}$ for the hydrogen release step.
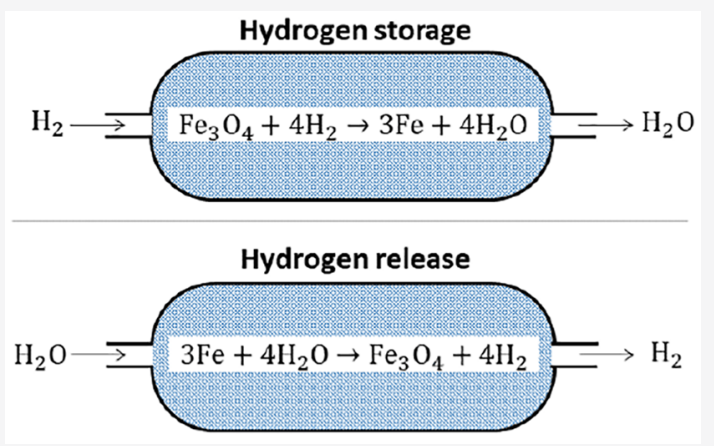
The energy demand of the storage was calculated to be $27 \%$ of the lower heating value of hydrogen. Vis-a-vis other hydrogen storage methods, the iron-based storage exhibits drawbacks for on-board mobile applications but could be attractive for large-scale and long-term storage applications.

\section{INTRODUCTION}

Hydrogen produced from water using renewable energy has the potential to become a sustainable energy carrier. ${ }^{1,2}$ One challenge of hydrogen is that it is relatively difficult to store at a large scale and over extended periods. Options proposed include underground pressurized storage in the gas phase, storage in compressed hydrogen tanks, physisorption, and chemical hydrides. $^{3-5}$ An alternative approach is the thermochemical storage using a reversible metal oxide redox cycle with $\mathrm{H}_{2}$ as a reducing agent and $\mathrm{H}_{2} \mathrm{O}$ as an oxidizing agent, ${ }^{6,7}$ given by the reversible reaction

$$
\mathrm{Me}_{x} \mathrm{O}_{y}+z \mathrm{H}_{2} \leftrightarrow \mathrm{Me}_{x} \mathrm{O}_{y-z}+z \mathrm{H}_{2} \mathrm{O}(\mathrm{g})
$$

and illustrated in Figure 1 using iron oxide as an example. The oxidation reaction has been applied for high-purity hydrogen production. ${ }^{8}$ This storage route using iron oxide was proposed for application in fuel cell vehicles. ${ }^{9,10}$ However, on-board storage in $\mathrm{H}_{2}$-fueled vehicles sets stringent requirements on energy density, process conditions, and charging/discharging response times, ${ }^{11}$ which are unlikely to be met with this cyclic redox process. On the other hand, large-scale and long-term the storage can tolerate lower energy densities and slow charging/discharging rates, with the focus shifted more toward the cost of the storage medium and the safety and stability of the system in the charged state. ${ }^{12}$ In this regard, the process illustrated in Figure 1 is attractive due to the storage material's abundance and cost and the charged state's inherent stability as water/steam must be supplied for the hydrogen release. Metals

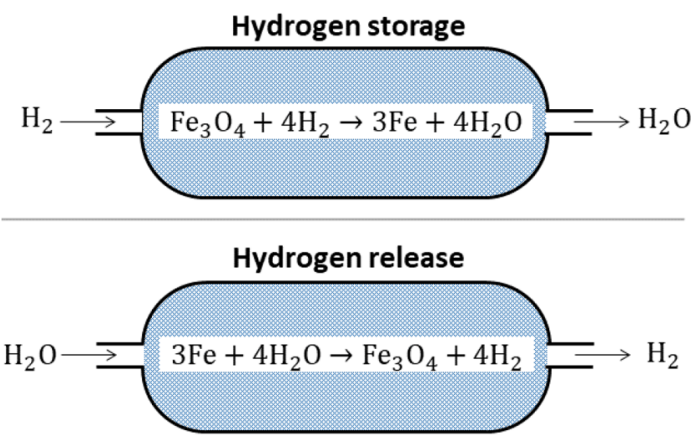

Figure 1. Schematic of hydrogen storage using the reversible reduction and oxidation of iron oxide $\mathrm{Fe}_{3} \mathrm{O}_{4}$, in a packed bed configuration serving as both chemical reactor and storage vessel.

have also been studied as energy carriers for the storage and transportation of renewable energy, ${ }^{7,13,14}$ with much knowhow and infrastructure already developed in the metallurgical industries.

Received: July 31,2021

Revised: September 27, 2021

Published: November 1, 2021 
Table 1. Comparison of Metal Oxides Redox Systems for Hydrogen Storage, Assuming a Complete Stoichiometric Reduction and Oxidation ${ }^{a}$

\begin{tabular}{|c|c|c|c|c|c|c|}
\hline \multirow[b]{2}{*}{ redox cycle } & \multicolumn{2}{|c|}{ process conditions } & energy demand & \multirow[b]{2}{*}{ material cost, $\$ / \mathrm{kg}_{\mathrm{H}_{2}}$} & \multicolumn{2}{|c|}{ storage density } \\
\hline & $T_{\text {red }}\left(x_{\mathrm{H}_{2} \mathrm{O}}>0.1\right),{ }^{\circ} \mathrm{C}$ & $T_{\mathrm{ox}}\left(x_{\mathrm{H}_{2}}>0.5\right),{ }^{\circ} \mathrm{C}$ & $\Delta_{\mathrm{r}} H^{\circ}{ }_{298 \mathrm{~K}}, \mathrm{~kJ} / \mathrm{mol}_{\mathrm{H}_{2}}$ & & wrt metal, (wt \%) $)_{\mathrm{H}_{2}}$ & wrt metal oxide, $(\text { wt } \%)_{\mathrm{H}_{2}}$ \\
\hline $\mathrm{Fe}_{3} \mathrm{O}_{4} / \mathrm{Fe}$ & $>420$ & $<670$ & 38 & 4 & 4.8 & 3.5 \\
\hline $\mathrm{ZnO} / \mathrm{Zn}$ & $>1055$ & $<1220$ & 109 & 81 & 3.1 & 2.5 \\
\hline $\mathrm{SnO}_{2} / \mathrm{Sn}$ & $>365$ & $<555$ & 47 & 1001 & 3.4 & 2.7 \\
\hline $\mathrm{GeO}_{2} / \mathrm{Ge}$ & $>425$ & $<750$ & 48 & 36037 & 5.5 & 3.9 \\
\hline $\mathrm{WO}_{2.722} / \mathrm{W}$ & $>590$ & $<640$ & 39 & 358 & 3.0 & 2.4 \\
\hline $\mathrm{MoO}_{2} / \mathrm{Mo}$ & $>590$ & $<1110$ & 52 & 476 & 4.2 & 3.2 \\
\hline
\end{tabular}

${ }^{a_{T}}$ Thermodynamic data: for Fe, Spreitzer and Schenk ${ }^{16}$ and the NIST Chemistry WebBook; for Zn and Sn, Factsage; ${ }^{30}$ for Ge, W, and Mo, Thaler and Hacker ${ }^{6}$ and the NIST Chemistry WebBook. For a lack of data, $\Delta_{\mathrm{f}} \mathrm{H}^{\circ}{ }_{\mathrm{WO}_{3}}$ is used instead of $\Delta_{\mathrm{f}} \mathrm{H}^{\circ}{ }_{\mathrm{WO}_{2.722}}$ and normalized per mole of hydrogen, to approximate $\Delta_{\mathrm{r}} \mathrm{H}^{\circ}$ for the $\mathrm{WO}_{2.722} / \mathrm{W}$ reaction. Material cost based on metal prices is available on publicly accessible exchanges and websites: iron, zinc, and molybdenum prices from Trading Economics (www.tradingeconomics.com), tin price from London metal exchange (www.lme. com), germanium price from Statistica (www.statistica.com), tungsten price from Metalary (www.metalary.com). All accessed on 2020-09-18.

In this work, we report a technical analysis of this hydrogen storage concept, which contributes to the literature in several ways. First, we screen the suitability of various metal oxides and select iron as a promising candidate material for further study. The screening criteria include the process temperatures determined from consideration of thermodynamic conversion extents, the enthalpy change of the reactions (representing energy demand), the material stability against sintering, and the raw material cost. Second, we develop a thermodynamic model to determine favorable process conditions. Third, we review and interpret the existing literature on the kinetics and stability of iron oxide chemical looping with regard to its significance for hydrogen storage. Finally, we also perform a detailed comparison with other hydrogen storage technologies to elucidate benefits and drawbacks. For this comparison, we use several key performance indicators frequently employed in the hydrogen storage literature, ${ }^{5,15}$ namely, the process conditions pressure and temperature, the volumetric and gravimetric storage densities, and the energy demand. Here the material cost is also included as a performance indicator for cases using a chemical cycling process as the storage concept, such as the metal oxides considered here and the metal hydrides. While this does not reflect the actual cost of hydrogen storage, it is a valuable performance indicator as low material cost typically implies abundant supply and production of a material, which is clearly beneficial.

Although the hydrogen storage route proposed here has received little attention, the individual reaction steps have been studied in the context of other applications. The reduction reaction utilized in the hydrogen storage step has been studied for iron production via the direct reduction of iron oxides with $\mathrm{H}_{2}{ }^{16-18}$ The oxidation reaction has been extensively researched in the field of chemical looping hydrogen production $(\mathrm{CLH})^{19,20}$ and solar thermochemical splitting of $\mathrm{H}_{2} \mathrm{O} .^{21-23}$ While these applications are similar, the choice of materials and process conditions for hydrogen storage will likely be quite different. The redox materials in CLH and thermochemical fuel production are continuously looped at a high turnover rate. Thus, many studies have focused on increasing the oxygen carriers' kinetics and cycling stability, ${ }^{19,20}$ often at the expense of storage density. Furthermore, some materials proposed for CLH and thermochemical hydrogen production undergo partial reduction resulting in a low storage density and thus are not suitable for application in hydrogen storage. Examples of such materials are perovskites and cerium-based oxides. ${ }^{24-26}$ Another major difference is the process temperatures, where all of the above applications operate at high temperatures above $600{ }^{\circ} \mathrm{C}, 27,28$ which would not be practical for hydrogen storage. Lower temperatures would likely benefit the energy demand and increase the material's cycling stability. The lower temperature comes at the expense of slower kinetics, which are less critical for long-term hydrogen storage.

\section{METAL OXIDE SELECTION}

A recent literature review on $\mathrm{CLH}$ concluded that iron-based materials are the best candidates for hydrogen production, citing several studies that compared metal oxides based on feedstock conversion extents, kinetics, cycling stability, physical strength, cost, toxicity, and environmental effects. ${ }^{20}$ Much of the same logic can be used to select metal oxides for hydrogen storage, and indeed iron oxide has also been studied for this application. ${ }^{9,10,29}$ Here we perform a further screening due to a shift in focus on the desired properties relative to CLH.

We quantitatively compare several redox pairs with the inclusion of storage density and the material cost as screening criteria. Besides these metrics, the redox pairs are compared on the basis of process conditions and the minimum energy demand of the storage step (eq 1), which is the enthalpy change of the reduction reaction per mole of $\mathrm{H}_{2}, \Delta_{\mathrm{r}} \mathrm{H}$. The results are presented in Table 1 . The redox pairs $\mathrm{Fe}_{3} \mathrm{O}_{4} / \mathrm{Fe}$, $\mathrm{ZnO} / \mathrm{Zn}, \mathrm{SnO}_{2} / \mathrm{SnO}, \mathrm{GeO}_{2} / \mathrm{Ge}, \mathrm{WO}_{2.722} / \mathrm{W}$, and $\mathrm{MoO}_{2} / \mathrm{Mo}$ were chosen because the change in the standard Gibbs free energy of the reduction reaction, $\Delta_{\mathrm{r}} G^{\circ}$, allows for a reversible redox process at reasonable temperatures. ${ }^{6}$

The process conditions are estimated on the basis of thermodynamic limitations on the conversion extent of $\mathrm{H}_{2}$ and $\mathrm{H}_{2} \mathrm{O}$ in eq 1 . The equilibrium condition for both forward and reverse reactions given in eq 1 , is given by

$$
\Delta_{\mathrm{r}} G(T)=\Delta_{\mathrm{r}} G^{\circ}(T)+R T \ln \left(\frac{x_{\mathrm{H}_{2} \mathrm{O}}}{x_{\mathrm{H}_{2}}}\right)=0
$$

where $\Delta_{\mathrm{r}} G^{\circ}$ is the standard change in Gibbs free energy of the reaction per mole of hydrogen and $x_{i}$ denote the mole fractions of steam and hydrogen in the gas phase. A more detailed derivation of this expression is given in the Supporting Information (SI), where we assume ideal gas behavior, incompressible solids, and no solid solutions (mixing) in the solid phases. In this way, the activities of the solid phases can be set equal to one, so they are omitted from the equilibrium 
constant. It is important to note that the equilibrium equation then only depends on the temperature and the ratio of $\mathrm{H}_{2}$ to $\mathrm{H}_{2} \mathrm{O}$ in the gas phase. Under these assumptions, the process thermodynamics are independent of pressure, which should be a good approximation within practically relevant pressure limits.

Using the thermodynamic equilibrium condition and setting minimum criteria on the conversion extent of the hydrogen and steam in each step, we can set lower and upper bounds on $T_{\text {red }}$ and $T_{\text {ox }}$. To do this, we apply the criteria $x_{\mathrm{H}_{2} \mathrm{O}}>0.1$ for the reduction process and $x_{\mathrm{H}_{2}}>0.5$ for the oxidation process. In other words, we want a minimum of $10 \%$ conversion of the hydrogen during reduction and $50 \%$ conversion of the steam during oxidation. While somewhat arbitrary, these criteria were chosen because they are expected to yield reasonable process efficiencies. The conversion extent is more critical during oxidation because excess unreacted steam is energetically expensive to produce and must be condensed out of the product $\mathrm{H}_{2}$.

The results of the screening are presented in Table 1. From the perspective of process conditions, both zinc and tin are unfavorable candidates because of phase changes that exist below the minimum reduction temperature, $T_{\text {red }}$. The standard enthalpy change of the reaction, $\Delta_{\mathrm{r}} H^{\circ}{ }_{298 \mathrm{~K}}$ gives the minimum energy demand. All candidates except for zinc are comparable in this regard. Gravimetric storage density indicates germanium as the best candidate, followed closely by iron. However, the cost of germanium is several orders of magnitude more than iron. Indeed, the raw material cost of most options is higher than the estimated cost of a gaseous hydrogen storage vessel in the range of $\$ 200-333 / \mathrm{kg}_{\mathrm{H}_{2}}{ }^{31}$ Considering both the previous analyses in the literature and the additional comparison in this work, iron oxide is selected as a promising candidate for hydrogen storage and as the subject of the remainder of the study.

\section{THERMODYNAMICS}

We develop a thermodynamic model and use it to determine suitable process temperatures and the energy demand of hydrogen storage using iron oxide. The redox reaction at temperatures below $570{ }^{\circ} \mathrm{C}$ is given by

$$
\mathrm{Fe}_{3} \mathrm{O}_{4}+4 \mathrm{H}_{2} \rightleftharpoons 3 \mathrm{Fe}+4 \mathrm{H}_{2} \mathrm{O}(\mathrm{g})
$$

Above $570{ }^{\circ} \mathrm{C}$, wustite $(\mathrm{FeO})$ formation is favorable as an intermediate product, as can be seen in the phase diagram shown in Figure 2 of Spreitzer and Schenk's review. ${ }^{16}$ For the application of hydrogen storage, we only consider temperatures below $570{ }^{\circ} \mathrm{C}$ and therefore omit $\mathrm{FeO}$ formation from the analysis. The redox system is then a single step reversible reaction between $\mathrm{Fe}_{3} \mathrm{O}_{4}$ and $\mathrm{Fe}$. The equilibrium thermodynamics for the process then fixes the equilibrium mole fractions of the gas phase for a given temperature, which is plotted in Figure 2. It can be seen that the reduction reaction, forming $\mathrm{H}_{2} \mathrm{O}$, will be less favorable due to the lower mole fraction of $\mathrm{H}_{2} \mathrm{O}$, while the oxidation reaction will be very favorable in this temperature range.

The reduction and oxidation processes are modeled independently as steady-state continuous processes. The model considers heating of the reactants, the redox reaction proceeding until equilibrium, and cooling of the products. The reactions are assumed to go to equilibrium values seen in Figure 2. The equilibrium is used to determine the excess of

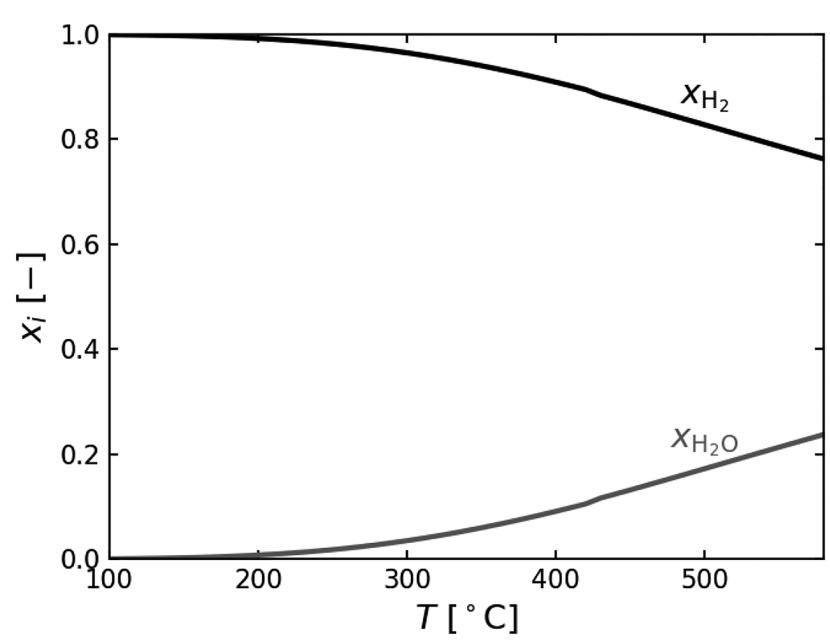

Figure 2. Equilibrium mole fractions $x_{i}$ of hydrogen and steam for the reversible redox reaction given by eq 3 , which were calculated according to eq 2 .

hydrogen or steam required for each step. Process flow diagrams for the hydrogen storage and release processes via eq 3 can be seen in Figure 3.

Heat is required for both the processes of storing and releasing hydrogen. These energy demands are quantified in a dimensionless relative energy demand defined as

$$
\beta=\beta_{\text {storage }}+\beta_{\text {release }}=\frac{Q_{\text {storage }}+Q_{\text {release }}}{L_{H V} \mathrm{H}_{2}} \times 100 \%
$$

where $Q_{\text {storage }}$ and $Q_{\text {release }}$ are the quantities of external heat required per mole of hydrogen for the storage and release steps, respectively, and $\mathrm{LHV}_{\mathrm{H}_{2}}$ is the lower heating value of hydrogen. Electric energy consumption from gas pumping or solid handling is neglected, consistent with similar literature. ${ }^{17}$ The processes are modeled at atmospheric pressure, but since the reaction thermodynamics are independent of pressure according to eq 2 , the energy demand results should also be indicative of higher pressure operation. Complete details for the calculations of $Q_{\text {storage }}$ and $Q_{\text {release }}$ are given in the SI. In each case, the sensible heat of the product species is recovered with an efficiency $\eta_{Q}$, while the heat of condensation is considered to be lost. The endothermic reduction will always require a heat input leading to a minimum energy demand of $\beta_{\text {storage }}=15.5 \%$. In contrast, the exothermic oxidation delivers much of the heat needed for the release process, reducing the relative energy demand $\beta_{\text {release }}$. The hydrogen storage process was only considered for temperatures above $300{ }^{\circ} \mathrm{C}$, as below this value the conversion of hydrogen to steam is very low (see Figure 2). This results in very low steam mole fractions, and the condensation step would require cooling below ambient temperature.

Instead of oxidation by steam, iron can also be oxidized by liquid water via the same reaction given in eq $3 . .^{32-34} \mathrm{~A}$ simplified process flow diagram for this alternative release process as well as the model details used to calculate the relative energy demand $\beta_{\text {release, } \mathrm{H}_{2} \mathrm{O}(\mathrm{l})}$ can be found in the SI. This system is potentially simpler because it does not include an evaporator. A condenser is still required as unreacted water vapor will still be present in the product gas. A detailed derivation of the reaction thermodynamics is given in the SI. The equilibrium hydrogen pressure is fixed by the temperature. 

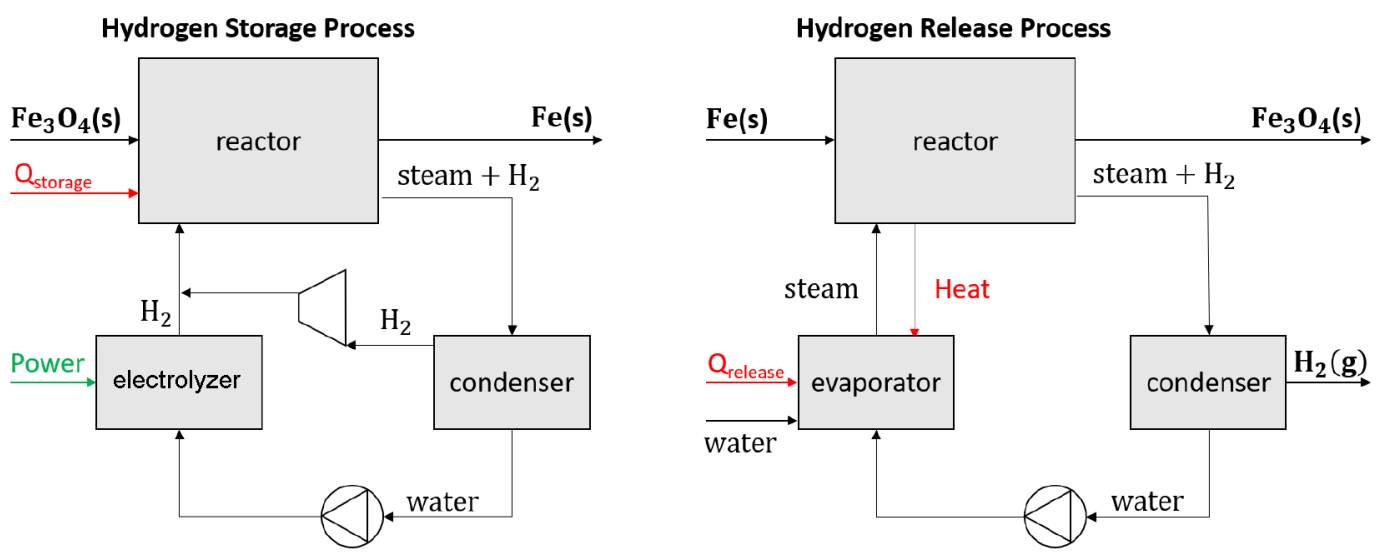

Figure 3. Flow diagram for the hydrogen storage and release processes via iron oxide reduction and iron oxidation, respectively. Note that the electrolysis system in the storage step is not included in the thermodynamic model. It was added to illustrate the process configuration and the potential to have a closed-loop mass balance for hydrogen and steam, meaning that an external water supply is not needed during the reduction step.

However, the equilibrium hydrogen pressure would be impractically high for the considered temperature range, with $p_{\mathrm{H}_{2} \text {,equilibrium }}>1400 \mathrm{bar}$. Therefore, the total pressure was instead fixed at a lower value with two cases considered, $p=15$ bar and $p=150$ bar. The product gas mixture was then determined by assuming that steam will also be present in the gas phase at its saturation pressure,

$$
p=p_{\mathrm{H}_{2}}+p_{\mathrm{H}_{2} \mathrm{O}}^{\mathrm{sat}}(T)
$$

The unreacted steam in the products results in a thermal energy demand that increases with temperature, due to the exponentially increasing saturation pressure of steam.

The model was built using the Cantera software package for Python, ${ }^{35}$ while thermodynamic data for chemical species were obtained from the NIST Chemistry WebBook. A more detailed explanation of the model can be found in the SI.

3.1. Modeling Results. The relative energy demands, $\beta$, for the hydrogen storage and release processes are shown in Figure 4 . The storage energy demand, $\beta_{\text {storage, }}$ rises sharply with

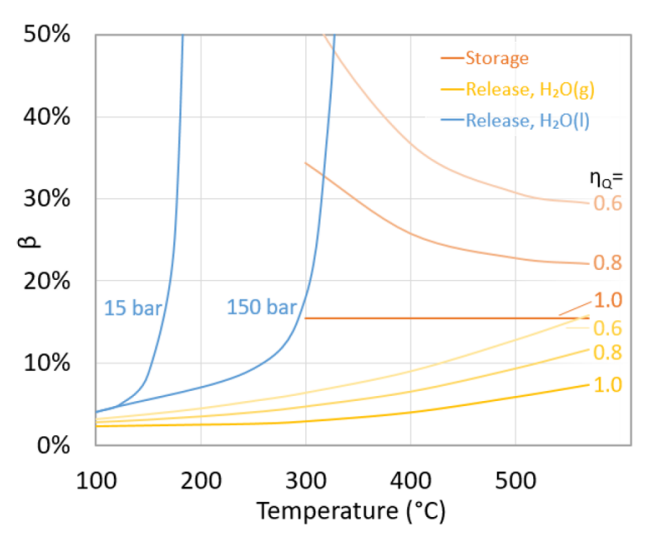

Figure 4. Relative energy demand, $\beta$, of the storage and release process steps are plotted vs the temperature for the hydrogen storage step (orange lines), the hydrogen release using steam (yellow lines), and the hydrogen release using liquid water (blue lines). A number of different values of heat recovery efficiency, $\eta_{\mathrm{Q}}$, were considered for the storage and release using steam, as labeled on the right. For the release using liquid water, operating pressures of both 15 and 150 bar were considered, with a heat recovery efficiency of $\eta_{Q}=0.8$. decreasing temperatures because of the decreasing conversion of $\mathrm{H}_{2}$ to $\mathrm{H}_{2} \mathrm{O}$ (see Figure 2), which causes a large excess of hydrogen to be recycled with repeated heating and cooling resulting in thermal losses. This relatively low conversion of hydrogen and large recycle flow also explains the strong dependence of $\beta_{\text {storage }}$ on the heat recovery efficiency, $\eta_{Q}$. In the case of ideal heat recovery, $\eta_{Q}=1$, all sensible heat requirements are met with heat recovery and $Q_{\text {storage }}$ reaches a theoretical minimum value which is equal to the enthalpy of reaction. At $400{ }^{\circ} \mathrm{C}$ the conversion of $\mathrm{H}_{2}$ to $\mathrm{H}_{2} \mathrm{O}$ is approximately $9 \%$ and the net sensible heat demand is 118.4 $\mathrm{kJ} \mathrm{mol}_{\mathrm{H}_{2}}{ }^{-1}$. The sensible heat available in the products (excluding the heat of condensation) is $112.3 \mathrm{~kJ} \mathrm{~mol}_{\mathrm{H}_{2}}{ }^{-1}$, $93 \%$ of which is the sensible heat contained in the off gas. With efficient gas-phase heat recovery, the process could approach the ideal case allowing for operation at such low temperatures.

Conversely, the hydrogen release process is thermodynamically more favorable at lower temperatures because the thermodynamic conversion extent of $\mathrm{H}_{2} \mathrm{O}$ to $\mathrm{H}_{2}$ increases with decreasing temperature. However, losses still remain with ideal heat recovery $\eta_{Q}=1$, because latent heat from condensing unreacted steam is assumed to be lost. For the oxidation of iron with $\mathrm{H}_{2} \mathrm{O}(\mathrm{l})$, the energy demand increases with increasing temperature, which is a result of the steam saturation pressure, $p_{\mathrm{H}_{2} \mathrm{O}}^{\text {sat }}$, increasing exponentially with temperature, leading to an increased latent heat demand. As the saturation pressure, $p_{\mathrm{H}_{2} \mathrm{O}}^{\text {sat }}$, approaches the system pressure, the energy demand goes to infinity, as the gas phase becomes pure steam. Increasing the pressure for oxidation with $\mathrm{H}_{2} \mathrm{O}(1)$, reduces the energy demand, because the total pressure increases while the steam saturation pressure remains constant, leading to a lower steam mole fraction in the products.

The oxidation has a lower energy demand with $\mathrm{H}_{2} \mathrm{O}(\mathrm{g})$ than with $\mathrm{H}_{2} \mathrm{O}(\mathrm{l})$, due to the exponential increase in steam saturation pressure, leading to large amounts of unreacted steam in the products for the case of liquid water oxidation. Steam oxidation on the other hand has very favorable thermodynamics at the temperatures considered. For this reason and the lower availability of literature on oxidation with liquid water, we consider steam oxidation to be the preferred hydrogen release process. From a thermodynamic point of 


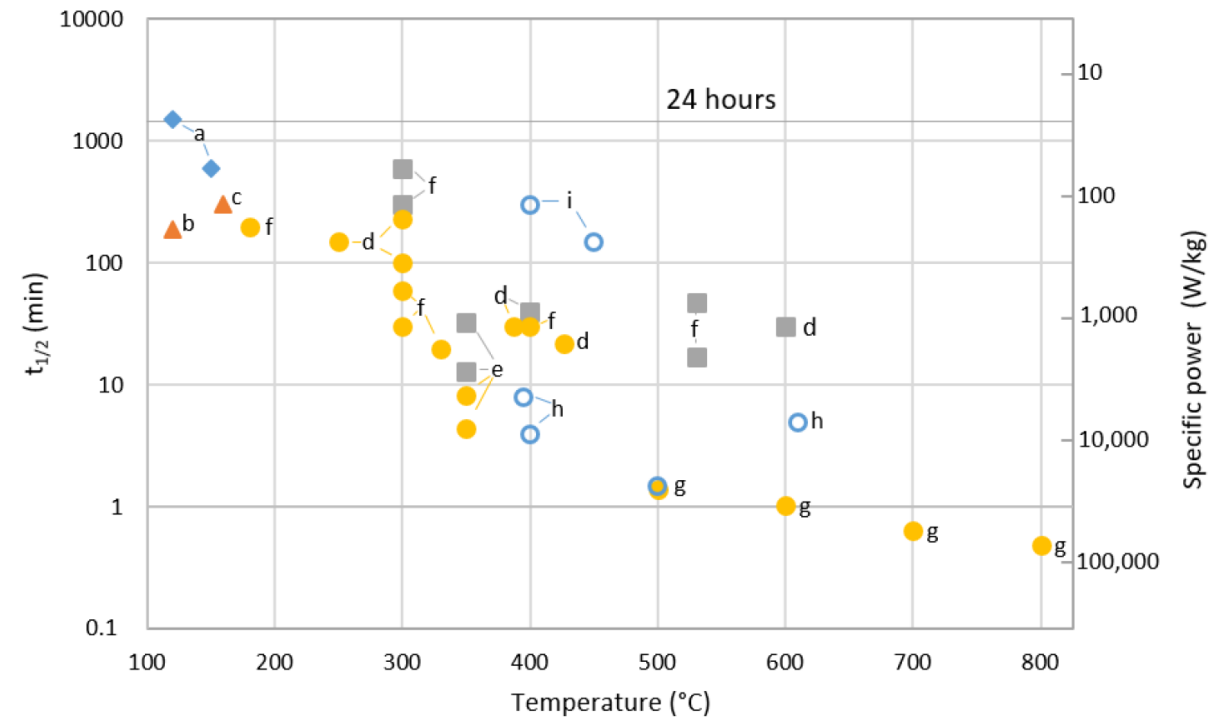

- Oxidation in water, pure iron

$\triangle$ Oxidation in water, catalyzed

Oxidation in steam, pure iron

o Reduction in $\mathrm{H}_{2}$, various iron-based materials

Figure 5. Approximate times, $t_{1 / 2}$, for reaching $50 \%$ conversion vs temperature for kinetic rates obtained from the literature and detailed in Table 2 . The right-hand $y$-axis shows the specific power calculated according to eq 6 . Kinetic data: a, from ref 33; b, from ref 49; c, from ref 32; d, from ref 9; e, from ref 10 ; f, from ref 41 ; h, from ref 43 ; i, from ref 44 .

view, the release step via steam oxidation could be performed at temperatures in the range $100-500{ }^{\circ} \mathrm{C}$, after which energy demand increases more rapidly due to the decreasing conversion of $\mathrm{H}_{2} \mathrm{O}$ to $\mathrm{H}_{2}$. The reduction, on the other hand, is more favorable above $400{ }^{\circ} \mathrm{C}$, due to the $\mathrm{H}_{2}$ to $\mathrm{H}_{2} \mathrm{O}$ conversion extent decreasing at lower temperatures. Assuming temperatures of 550 and $300{ }^{\circ} \mathrm{C}$ for the storage and release processes, respectively, and a heat recovery efficiency of $\eta_{Q}=$ 0.8 , the relative energy demand for hydrogen storage would be $\beta=\beta_{\text {storage }}+\beta_{\text {release }}=22.2 \%+4.7 \%=26.9 \%$ on the basis of the same results shown in Figure 4. We consider a relative energy demand of $27 \%$ when comparing iron-based hydrogen storage to other hydrogen storage routes.

If the oxide is not completely converted to iron, the relative energy demand will increase further. From section 6.1, a reasonable expected conversion extent for the iron oxide is $72 \%$, which increases the sensible heating demand of the solids and yields $\beta=22.8 \%+4.9 \%=27.7 \%$. This is only a slight increase as the larger share of thermal energy demand comes from the reaction and the gas-phase heat recovery. Limiting the conversion extent of the gas to $90 \%$ of its equilibrium value yields a more pronounced increase in energy demand to $\beta=$ $23.2 \%+6.7 \%=29.9 \%$. This value can be considered a sensitivity test, as the expected conversion extent could not be accurately estimated on the basis of the reviewed literature.

The hydrogen for the storage process could be provided by water electrolysis, for which polymer exchange membrane electrolysis and alkaline electrolysis are currently the most viable options. ${ }^{4}$ However, there are also a number of emerging high-temperature hydrogen production processes such as solid oxide electrolysis cells, ${ }^{36}$ and solar thermochemical routes including methane cracking, ${ }^{37,38}$ steam re-forming of methane, $^{39}$ and thermochemical redox cycles. ${ }^{40}$ These higher temperature processes have interesting synergies when combined with the hydrogen storage system proposed here, because of the availability of high-temperature hydrogen and steam, and the possibility of using concentrated solar energy to supply the heat. Heat management in the integrated system could reduce the energy demand.

\section{KINETICS}

For the hydrogen storage and release processes to be feasible, the oxidation and reduction reactions must proceed with an acceptable rate for the given storage application. Both steps in this cycle involve solid-gas reactions, which depend on temperature and pressure, the macro- and microstructure of the solid phase, and the heat and mass transfer characteristics of the chemical reactor configuration. The reaction rate can be limited by the surface reaction rate (adsorption, desorption, and reaction), gas-phase species transport, solid-phase species transport, and heat transfer. ${ }^{8,16,41,42}$ In this section, the kinetic rates of the reduction and oxidation steps with iron-based materials are assessed by reviewing the literature.

On the basis of the thermodynamic model developed in section 3 , reduction and oxidation temperatures should be $T_{\text {red }}$ $\geq 420{ }^{\circ} \mathrm{C}$ and $T_{\text {ox }}=100-500{ }^{\circ} \mathrm{C}$, respectively, to result in a reasonably low energy demand. Therefore, the discussion of reduction kinetics in this work focuses on the temperature range above but close to $400{ }^{\circ} \mathrm{C}$. Reduction kinetics are evaluated for different temperatures by Pineau et al., ${ }^{43}$ Teplov, $^{44}$ and Bleeker. ${ }^{41}$ Steam-iron oxidation has been heavily researched in the field of chemical looping, with temperatures usually upward of $500{ }^{\circ} \mathrm{C}$ considered. ${ }^{19,27,41}$ Only a limited number of studies have investigated steam-iron oxidation at temperatures in the range $100-500{ }^{\circ} \mathrm{C}$, and are the focus of this work. ${ }^{9,45-48}$ Iron can also be oxidized with liquid water instead of steam, commonly referred to as hydrothermal oxidation of iron. ${ }^{3,34}$ Several methods of catalyzing this hydrothermal oxidation reaction have also been explored. ${ }^{32,49-53}$

Kinetic data for oxidation and reduction extracted from the aforementioned literature are shown in Figure 5, which plots 
Table 2. References Used for Kinetic Data and Details of the Experiments, Including the Temperature, $t_{1 / 2}$, Support Materials, Particle Size, Surface Area, Location of the Data in the Referenced Work, and Whether or Not Extrapolation Was Used to Determine $t_{1 / 2}{ }^{a}$

\begin{tabular}{|c|c|c|c|c|c|c|c|c|}
\hline reacn & ref & $T,{ }^{\circ} \mathrm{C}$ & $t_{1 / 2}, \min$ & support/conditions & particle size, $\mu \mathrm{m}$ & surface area, $\mathrm{m}^{2} / \mathrm{g}$ & figure no. & extrapolated \\
\hline \multirow[t]{4}{*}{ oxidation with water } & 29 & 120 & 1500 & none & 3 & $0.26^{c}$ & 3,4 & yes \\
\hline & & 150 & 600 & none & 4 & $0.26^{c}$ & 3,4 & no \\
\hline & 42 & 120 & 187.5 & $0.01 \mathrm{M} \mathrm{HCI}$ & 45 & & 1 & no \\
\hline & 28 & 160 & 300 & $\mathrm{CO}_{3}{ }^{2-}(\mathrm{aq})$ & 5 & $0.15^{c}$ & 10 & no \\
\hline \multirow[t]{18}{*}{ oxidation with steam } & 9 & 400 & 40 & none & & 20 & 2 & yes $^{b}$ \\
\hline & & 600 & 30 & none & & $\approx 2$ & 2 & yes $^{b}$ \\
\hline & & 250 & 150 & various additives & & $\mathrm{O}(10)$ & 4,6 & yes $^{b}$ \\
\hline & & 300 & $100-231$ & various additives & & $\mathrm{O}(10)$ & 4,6 & yes $^{b}$ \\
\hline & & 387 & 30 & $\mathrm{Al}_{2} \mathrm{O}_{3}$ & & $\mathrm{O}(10)$ & 4 & yes $^{b}$ \\
\hline & & 427 & 22 & $\mathrm{MoO}_{3}$ & & $\mathrm{O}(10)$ & 4 & yes $^{b}$ \\
\hline & 10 & 350 & $13-33$ & none & & $2-20$ & 4 & no \\
\hline & & 350 & $4.44-8.33$ & various additives & & $7-23$ & 4 & no \\
\hline & 41 & 300 & $300-600$ & none & & $1-8$ & Table 1 & yes $^{b}$ \\
\hline & & 180 & 200 & $\mathrm{Al}_{2} \mathrm{O}_{3}$ & & 0.5 & 2 & yes $^{b}$ \\
\hline & & 530 & $17-48$ & none & & $1.8-8$ & Table 2 & yes $^{b}$ \\
\hline & & 300 & $30-60$ & $\mathrm{Al}_{2} \mathrm{O}_{3} / \mathrm{MoO}_{3}$ & & 0.5 & Table 2 & yes $^{b}$ \\
\hline & & 330 & 20 & $\mathrm{MoO}_{3}$ & & 3 & Table 3 & yes $^{b}$ \\
\hline & & 400 & 30 & $\mathrm{Al}_{2} \mathrm{O}_{3}$ & & 2.5 & Table 3 & yes $^{b}$ \\
\hline & 34 & 500 & 1.39 & $9 \% \mathrm{Cr}_{2} \mathrm{O}_{3}$ and $3 \% \mathrm{CuO}$ & $125-200$ & 4.67 & 5,17 & no \\
\hline & & 600 & 1.04 & $9 \% \mathrm{Cr}_{2} \mathrm{O}_{3}$ and $3 \% \mathrm{CuO}$ & $125-200$ & 4.67 & 5,17 & no \\
\hline & & 700 & 0.64 & $9 \% \mathrm{Cr}_{2} \mathrm{O}_{3}$ and $3 \% \mathrm{CuO}$ & $125-200$ & 4.67 & 5,17 & no \\
\hline & & 800 & 0.49 & $9 \% \mathrm{Cr}_{2} \mathrm{O}_{3}$ and $3 \% \mathrm{CuO}$ & $125-200$ & 4.67 & 5,17 & no \\
\hline \multirow[t]{6}{*}{ reduction with hydrogen } & 34 & 500 & 1.5 & $9 \% \mathrm{Cr}_{2} \mathrm{O}_{3}$ and $3 \% \mathrm{CuO}$ & $125-200$ & 31.3 & 5,11 & yes \\
\hline & 36 & 395 & 8 & none & $10-20$ & 0.1 & 10 & no \\
\hline & & 610 & 5 & none & $10-20$ & 0.1 & 10 & no \\
\hline & & 400 & 4 & none & $1-2$ & 0.7 & 2 & no \\
\hline & 37 & 400 & 300 & $\mathrm{Al}_{2} \mathrm{O}_{3}, \mathrm{MnO}, \mathrm{MgO}$ & pellets & & 4 & yes \\
\hline & & 450 & 150 & $\mathrm{Al}_{2} \mathrm{O}_{3}, \mathrm{MnO}, \mathrm{MgO}$ & pellets & & 4 & no \\
\hline
\end{tabular}

${ }^{a}$ The experiments were isothermal unless marked with a star indicating temperature ramp data were used. "figure no." refers to the figure number in the original publication. Where indicated, surface areas were calculated assuming smooth, solid, spherical particles and the density of iron. This estimation was only made when the literature described the particles as nonporous. ${ }^{b}$ Experiments used a temperature sweep rate of $4 \mathrm{~K} / \mathrm{min}$. Reaction rates from the respective temperature are used to calculate $t_{1 / 2} .{ }^{c}$ Calculated on the basis of particle size.

$t_{1 / 2}(\mathrm{~min})$ against temperature, where $t_{1 / 2}$ is defined as the time required to reach $50 \%$ conversion of the solid phase. More detailed information on the source data is presented in Table 2. When $50 \%$ conversion is not reached in the original data, the oxidation rates for lower conversion extents were extrapolated and these cases are labeled in Table 2. At around $400{ }^{\circ} \mathrm{C}$, reaching 50\% conversion took between 5 and $100 \mathrm{~min}$. Iron with additional support materials, such as $\mathrm{MoO}_{2}$ and $\mathrm{Al}_{2} \mathrm{O}_{3}$, generally shows faster kinetics and maintains higher rates at lower temperatures than pure iron. For reduction, the reaction rates found by separate studies differ significantly, spanning from near-complete reduction in minutes ${ }^{41,43}$ to $40 \%$ reduction after 4 h. ${ }^{44}$ These differences can largely be explained by the different morphology and composition of the iron oxides used in the experiments.

Figure 5 additionally shows the specific power of the processes on its right $y$-axis, which is calculated using

$$
\begin{aligned}
& \text { specific power } /\left(\frac{\mathrm{W}}{\mathrm{kg}}\right) \\
& =\frac{\text { hydrogen storage density } \times \mathrm{LHV}_{\mathrm{H}_{2}}}{\text { conversion time }}
\end{aligned}
$$

For a first estimate of the power density, the conversion time is taken as twice the time it takes to reach $50 \%$ conversion. The storage density of iron is taken from section 6.1, where it will be discussed in more detail. Note that the power density disregards the weight of the reactor vessel and the water used in the release step. Note also that the specific power is in terms of the heating value of hydrogen which may be converted to useful energy with further efficiency losses, which would lead to a lower specific power.

The conversion time can be used to assess for which applications this storage method could be suitable. In a moving bed reactor, relatively short conversion times would be desirable to limit the size of the reactor. In a fixed bed, which could double as storage vessel and reactor vessel, the conversion time approximates the minimum duration for completely charging or discharging the storage unit. Charge and discharge times in long-term storage would be on the order of days and weeks, ${ }^{12}$ where the data in Figure 5 indicate that even the lowest temperatures studied, of close to $100{ }^{\circ} \mathrm{C}$ for oxidation and $550{ }^{\circ} \mathrm{C}$ for reduction, could be suitable in a packed bed reactor and storage vessel.

When interpreting the kinetic data in the literature, it is also important to consider whether the experimental conditions represent those expected in the proposed process. For example, the low-temperature steam-iron oxidation experiments were performed with low water vapor pressures of 1.5-200 mbar, so it is likely that kinetic rates would have been higher at higher 
Table 3. Comparison of Hydrogen Carriers Based on Storage Density, Process Conditions, Energy Demand, and Material Cost of the Base Material in the Cases of Metal Hydrides, LOHCs, and Iron Oxide ${ }^{a}$

\begin{tabular}{|c|c|c|c|c|c|c|c|c|}
\hline \multirow[b]{3}{*}{ category } & \multirow[b]{3}{*}{ technology } & & & \multicolumn{3}{|c|}{ process conditions } & \multirow[b]{3}{*}{$\beta,^{b} \%$} & \multirow[b]{3}{*}{ material cost, $\mathrm{g} / \mathrm{kg}_{\mathrm{H}_{2}}$} \\
\hline & & \multicolumn{2}{|c|}{ storage density } & \multicolumn{2}{|c|}{ storage } & \multirow{2}{*}{$\begin{array}{l}\text { release } \\
T\left({ }^{\circ} \mathrm{C}\right)\end{array}$} & & \\
\hline & & $\mathrm{kg}_{\mathrm{H}_{2}} / \mathrm{m}^{3}$ & $(\text { wt } \%)_{\mathrm{H}_{2}}$ & $P$ (bar) & $T\left({ }^{\circ} \mathrm{C}\right)$ & & & \\
\hline \multirow[t]{4}{*}{ hydrogen } & $\mathrm{H}_{2}(\mathrm{~g})$ at $100 \mathrm{bar}$ & 7.8 & & 100 & & & $3-5$ & \\
\hline & $\mathrm{H}_{2}(\mathrm{~g})$ at $200 \mathrm{bar}$ & 14 & & 200 & & & $4-6$ & \\
\hline & $\mathrm{H}_{2}(\mathrm{~g})$ at $700 \mathrm{bar}$ & 40 & & 700 & & & $6-8$ & \\
\hline & $\mathrm{H}_{2}(1)$ & 70 & & & -253 & & 18 & \\
\hline adsorption & adsorption & 48 & 7 & 40 & -176 & & 20 & \\
\hline \multirow[t]{3}{*}{ chemical hydrides } & $\mathrm{NH}_{3}$ & 123 & 17.7 & 250 & 400 & $>425$ & 22 & \\
\hline & $\mathrm{CH}_{3} \mathrm{OH}$ & 99 & 12.5 & 50 & 250 & $250^{d}$ & 25 & \\
\hline & $\mathrm{CH}_{2} \mathrm{O}_{2}$ & 53 & 4.4 & 105 & $100-180$ & $<100$ & 225 & \\
\hline \multirow[t]{3}{*}{ LOHCs } & MCH-TOL & 47 & 6.1 & 30 & 150 & $350^{d}$ & 36 & 8.2 \\
\hline & DBT-PDBT & 64 & 5.8 & 30 & 150 & 300 & 29 & 8.6 \\
\hline & NEC-DNEC & 54 & 5.8 & 30 & 150 & 220 & 25 & $?^{e}$ \\
\hline \multirow[t]{2}{*}{ metals } & $\mathrm{Fe}$ & $96.2 / 168.4^{c}$ & 4.81 & & $>400$ & $100-500$ & 27 & 4.2 \\
\hline & Fe-based & $69.3 / 121.3^{c}$ & 3.46 & & $>400$ & $100-500$ & 27 & 6.1 \\
\hline \multirow[t]{7}{*}{ metal hydrides } & $\mathrm{AlH}_{3}$ & $86^{c}$ & 10.1 & & $<70$ & 100 & 195 & 16 \\
\hline & $\mathrm{MgH}_{2}$ & $86^{c}$ & 6 & 30 & 300 & 350 & 33 & 37 \\
\hline & intermetallic hydride & $65^{c}$ & 1.5 & 50 & $<80$ & $<80$ & 14 & $>367$ \\
\hline & $\mathrm{NaAlH}_{4}$ & $54^{c}$ & 4 & 100 & 125 & 160 & 20 & 100 \\
\hline & $\mathrm{LiBH}_{4}-\mathrm{MgH}_{2}$ & $68^{c}$ & 9.1 & 50 & 350 & 350 & 22 & 1022 \\
\hline & $2 \mathrm{Li}\left(\mathrm{NH}_{2}\right)-\mathrm{MgH}_{2}$ & $54^{c}$ & 5.2 & 70 & 150 & 150 & $20 \%$ & $?^{e}$ \\
\hline & $\mathrm{NaBH}_{4}$ & $42.3^{c}$ & 4.2 & $?^{e}$ & $?^{e}$ & 20 & $\operatorname{high}^{e}$ & 595 \\
\hline
\end{tabular}

${ }^{a}$ While LOHCs are also chemical hydrides, they are here categorized separately from chemical hydrides because they are liquids. Values not explicitly stated in this work were taken from Andersson and Grönkvist. ${ }^{5} .{ }^{b} \beta$, energy demand. ${ }^{c}$ Volumetric storage density for single pellets. Values for pellets-in-bulk would be lower due to voids between pellets. ${ }^{d}$ Part of the heat can be supplied at $100{ }^{\circ} \mathrm{C}$. ${ }^{e}$ No precise estimate found in the reviewed literature.

vapor pressures. One issue with the kinetic studies of both oxidation and reduction steps is that they do not approach equilibrium conditions in the gas phase. They are typically performed in a thermogravimetric analysis setup with a constant inflow of water vapor or hydrogen, and the flow rate is typically high enough to keep the gas composition far away from equilibrium. The energy demand calculated in section 3 assumes equilibrium is reached in the gas phase and thus kinetic behavior as the system approaches equilibrium may be an issue. In a review of hydrogen reduction of iron oxides by Spreitzer and Schenk, the authors suggest that increased steam concentrations slow the reduction rates as water adsorbs to the surface blocking the adsorption of hydrogen. ${ }^{16}$ This effect increases with lower temperatures ${ }^{16}$ and may not be accurately represented in the kinetics considered here. Finally, many kinetic studies make use of powders. When such powders are pelletized, the total reaction time can be up to 15 times longer and conversion extents can be lower. ${ }^{27} \mathrm{~A}$ packed bed reactor would likely use pellets or granules to avoid large pressure drops across the reactor. Having said that, the kinetic rates are still promising, particularly if we consider long-term storage applications which could tolerate slower reaction times.

\section{CYCLING STABILITY}

Repeated cycling of the material can change the macro- and microstructure as a result of thermal sintering and fracturing, which is exacerbated by the large volume changes between the reduced and oxidized states. This in turn degrades the storage performance of the material over time in terms of both kinetic rates and conversion extents of the metal oxide. The cycling stability of oxygen carrier materials is therefore one of the main topics of chemical looping research. ${ }^{19,20,54}$ It is somewhat less critical for hydrogen storage as the material will spend significant time in storage instead of being cycled continuously as in chemical looping applications.

The cycling stability can be increased by adding support materials with a high melting point to resist sintering. ${ }^{8}$ The support materials can also be used to improve the mechanical stability. ${ }^{19,20,54} \mathrm{Al}_{2} \mathrm{O}_{3}$ and $\mathrm{ZrO}_{2}$ are among the most common support materials for iron-based oxygen carriers. ${ }^{19,20,54}$ Other additives that have shown positive effects on stability include $\mathrm{TiO}_{2}, \mathrm{SiO}_{2}, \mathrm{MgAl}_{2} \mathrm{O}_{4}$, ytrria-stabilized zirconia YSZ, $\mathrm{Cr}_{2} \mathrm{O}_{3}$, $\mathrm{MoO}_{3}, \mathrm{CeO}_{2}$, and perovskites. ${ }^{19,20}$ There are also good results with mixed oxides such as a mixture of $7.5 \mathrm{wt} \% \mathrm{SiO}_{2}, 5 \mathrm{wt} \%$ $\mathrm{Al}_{2} \mathrm{O}_{3}$, and $<2.5 \mathrm{wt} \% \mathrm{CaO}$ added to iron, which was stable under cycling at temperatures below $750{ }^{\circ} \mathrm{C} .{ }^{20}$ Such mixtures are commonly found in natural iron ores. ${ }^{55}$

Prolonged cycling with good kinetics for $\mathrm{CLH}$ was obtained with alumina supported iron pellets of 2-3 $\mathrm{mm}$ diameter consisting of $95 \mathrm{wt} \% \mathrm{Fe}_{2} \mathrm{O}_{3}$ and 5 wt $\% \mathrm{Al}_{2} \mathrm{O}_{3} \cdot{ }^{56}$ Upon redox cycling at $800{ }^{\circ} \mathrm{C}$, the conversion extent of the pellets started at approximately $79 \%$ of the theoretical maximum for the first cycle and decreased to $67 \%$ after 100 cycles. $^{27}$ For chemical looping, higher cycling stability can be preferred and some materials are stable for thousands of redox cycles. ${ }^{28}$ However, such high stability often comes with the trade-off of a lower conversion extent. ${ }^{19}$ For hydrogen storage, a high conversion extent is paramount, while a lower lifetime may be acceptable, particularly for longer-term storage. Moreover, the cycle life might be significantly increased at the lower temperatures suggested here of $<600{ }^{\circ} \mathrm{C}$. 


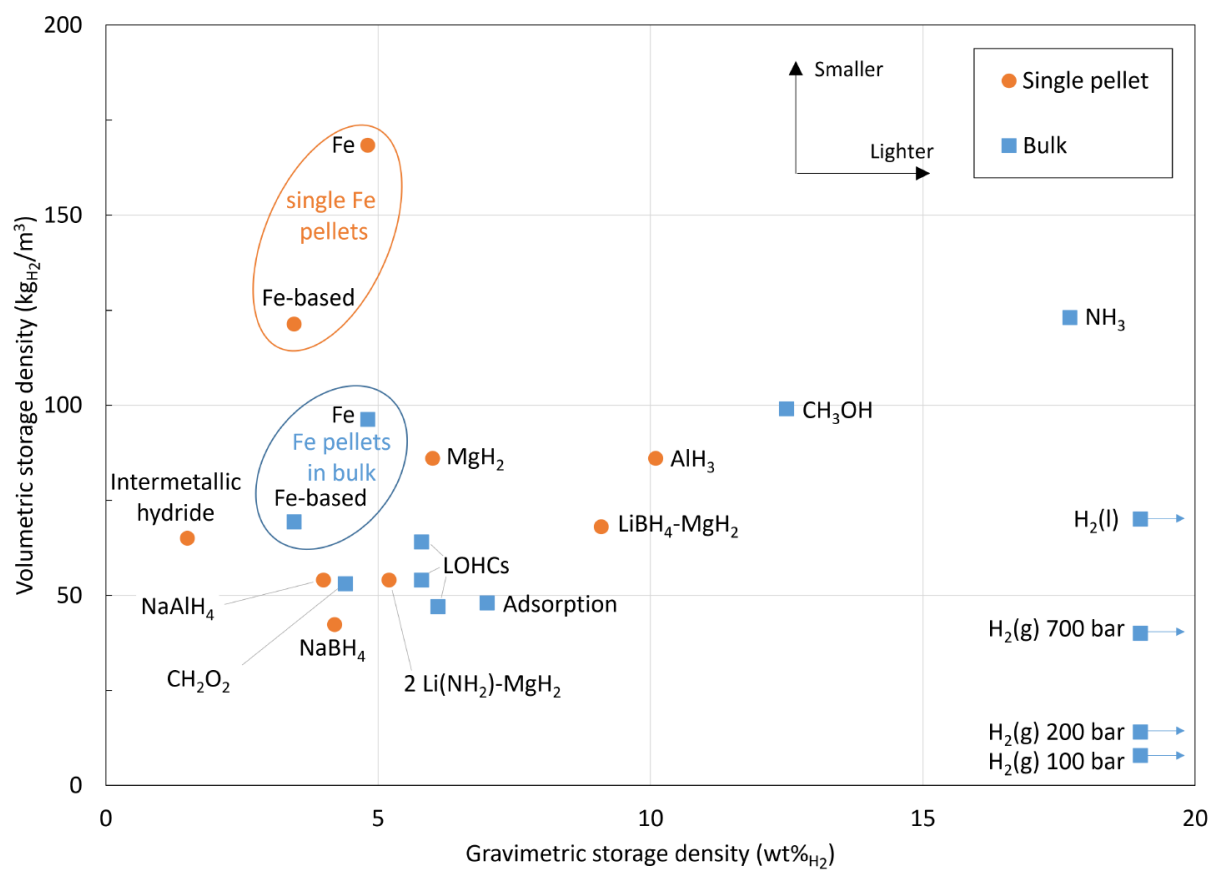

Figure 6. Gravimetric $\left((\mathrm{wt} \%)_{\mathrm{H}_{2}}\right)$ and volumetric $\left(\mathrm{kg}_{\mathrm{H}_{2}} / \mathrm{m}^{3}\right)$ storage densities of selected hydrogen storage technologies. The distinction between bulk and single pellet properties is important only for volumetric storage density. Compressed and liquefied hydrogen inherently have a gravimetric storage density of $(100 \mathrm{wt} \%)_{\mathrm{H}_{2}}$. Values for Fe taken from this work; other values adapted from Andersson and Grönkvist. ${ }^{5}$

In summary, the possibility of stabilizing iron-based oxygen carriers has been clearly demonstrated in the literature. The challenges in translating this research to hydrogen storage are in finding additives that are (i) particularly suited for cycling stability at lower temperatures; (ii) low cost; and (iii) minimize added weight, such that the storage density of the carrier remains high. $\mathrm{SiO}_{2}$ and $\mathrm{Al}_{2} \mathrm{O}_{3}$ are both particularly cheap additives that have shown good potential for stabilizing chemical looping materials. $8,27,57,58$

\section{COMPARISON OF HYDROGEN STORAGE METHODS}

Here the thermochemical storage of hydrogen using iron oxide is compared to several other hydrogen storage technologies, namely, physical storage in the form of compressed or liquefied hydrogen, physical adsorption, and chemical storage. The chemical storage methods included are various metal hydrides, liquid organic hydrogen carriers (LOHCs) such as toluene, ammonia, methanol, and formic acid. Detailed discussions of each route can be found in previous reviews. ${ }^{5,15}$ They have previously been compared on the basis of hydrogen storage densities, process conditions, and energy demand. ${ }^{5}$ This work includes the iron storage route described here and adds the cost of the storage material as an additional performance indicator.

Intermetallic hydrides and adsorption are included using representative technologies taken from an existing literature review on hydrogen storage. ${ }^{5}$ The metal hydrides and metal oxides are solid in both charged and discharged states. For example, when $\mathrm{AlH}_{3}$ is discharged, hydrogen is released and solid $\mathrm{Al}$ remains. LOHCs are liquids in both the charged and discharged states. LOHCs store hydrogen by chemical looping between their hydrogenated and dehydrogenated forms, for example, methylcyclohexane $(\mathrm{MCH})$ and toluene (TOL). In addition to the MCH-TOL cycle, the pairs dibenzyltoluene and perhydro-dibenzyltoluene (DBT-PDBT), and $\mathrm{N}$ ethylcarbazole and dodecahydro- $\mathrm{N}$-ethylcarbazole (NEC-DNEC) are included. Hydrogen storage by physical adsorption works by bringing hydrogen in contact with a large surface material, usually at very near cryogenic temperatures and high pressures, so the hydrogen adsorbs to the surface. Ammonia $\left(\mathrm{NH}_{3}\right)$, methanol $\left(\mathrm{CH}_{3} \mathrm{OH}\right)$, and formic acid $\left(\mathrm{CH}_{2} \mathrm{O}_{2}\right)$ are also included in the comparison as chemical hydrogen storage options.

In the subsequent sections, the selected hydrogen storage technologies are compared on the basis of the following performance indicators: hydrogen storage density, process conditions, energy demand, and storage material cost for the cyclic chemical processes using a solid- or liquid-based hydrogen carrier with the results summarized in Table 3.

6.1. Hydrogen Storage Density. Hydrogen storage technologies can be compared by their volumetric $\left(\mathrm{kg}_{\mathrm{H}_{2}} / \mathrm{m}^{3}\right)$ and gravimetric ( $(w t \%)_{\mathrm{H}_{2}}$ ) storage densities. This work uses four cases to reflect hydrogen storage using iron: single "Fe" pellets, single "Fe-based" pellets, "Fe" pellets-in-bulk, and "Fe-based" pellets-in-bulk. The "Fe" pellets consist of pure iron and react to full conversion extent, while the "Fe-based" pellets consist of iron with $10 \mathrm{wt} \%$ inert species and $80 \%$ maximum conversion extent. A further distinction is made between the single pellet level and the pellets-in-bulk level. The density of single iron(-based) pellets is assumed to be $3.5 \mathrm{~kg} / \mathrm{L}$, whereas the bulk density of those pellets in a packed bed formation is assumed to be $2 \mathrm{~kg} / \mathrm{L}$. The bulk density is lower than the single pellet density because it includes the voids between the pellets. The four resulting cases are tabulated in the SI. The energy densities for the other hydrogen storage technologies are taken from the literature. ${ }^{5}$

An overview of the hydrogen storage densities is shown in Figure 6. The weight and size of the storage vessel are not included for any of the technologies. For a fair comparison between iron and the other storage technologies, the "single pellet" values should be used for comparison with metal hydrides, which are also evaluated in single pellet form. Meanwhile, the "bulk" values for iron should be used for a fair comparison with compressed and liquefied hydrogen, adsorption, and chemical hydrides. Figure 6 shows that iron has a higher volumetric storage density than the reviewed metal hydrides, although it is considerably heavier than some. Compared to the other hydrogen storage technologies, iron has a similar volumetric storage density compared to many alternatives, although ammonia and methanol perform significantly better. In contrast, iron's gravimetric energy density is lower than most alternatives. 


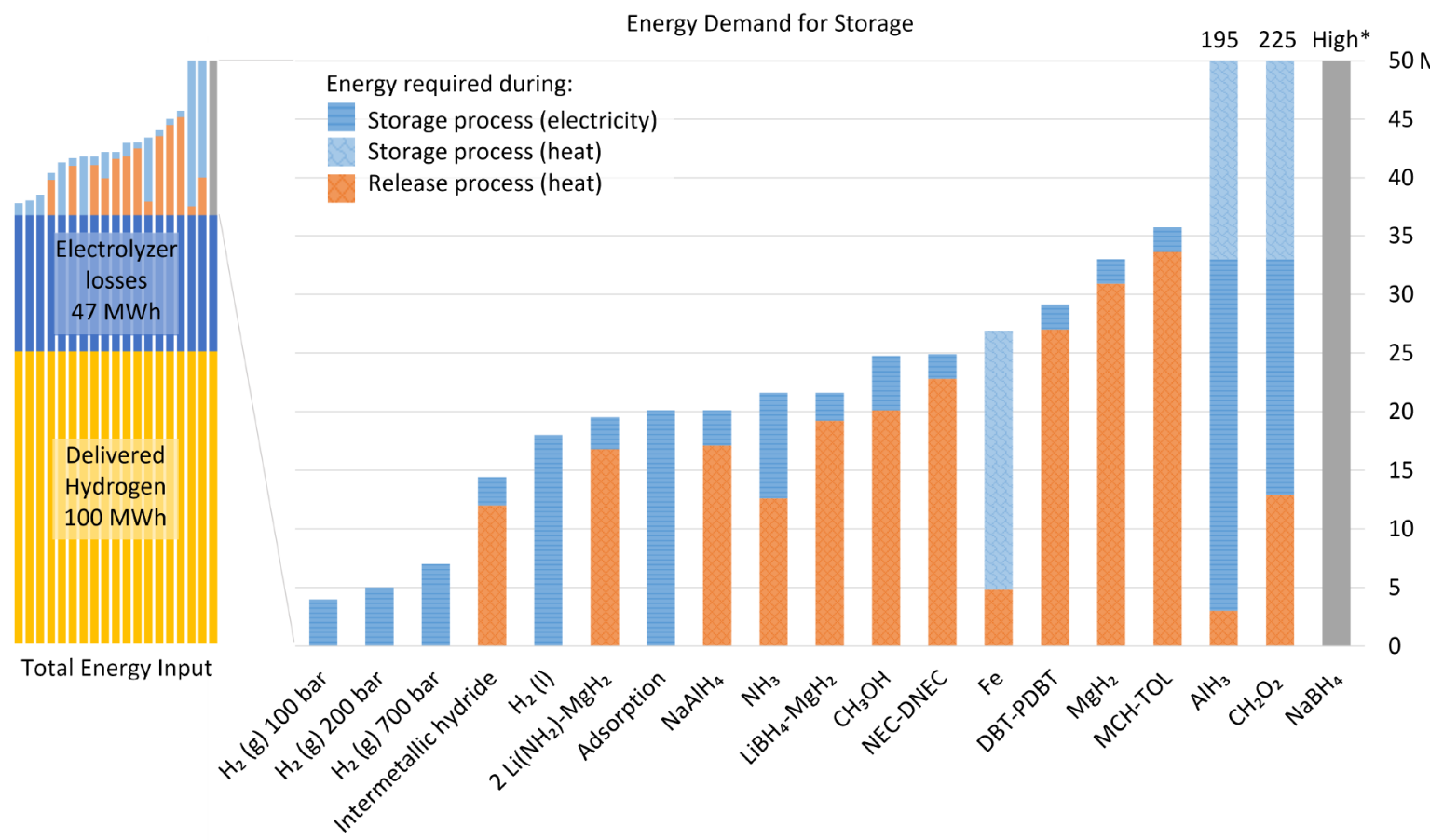

Figure 7. Energy demands for producing and storing $100 \mathrm{MWh}$ of green hydrogen for selected hydrogen storage technologies, with a relative comparison on the left to the energy demand of producing the hydrogen with an electrolysis efficiency of $68 \%{ }^{4}$ Values for Fe taken from this work; other values adapted from Andersson and Grönkvist. ${ }^{5}$ The asterisk $(*)$ indicates the energy demand for $\mathrm{NaBH}_{4}$ is not known but is expected to be high. ${ }^{5}$

It should be noted that the analysis of iron is based on the chargedstate $\mathrm{Fe}$. Calculating the gravimetric storage density of iron with respect to the heavier discharged-state $\mathrm{Fe}_{3} \mathrm{O}_{4}$ would yield lower values. Depending on the application, it could also be argued that the weight of water needed for the oxidation reaction should be included in the storage density calculation. Finally, the high volumetric storage density of gaseous hydrogen storage of $100(\mathrm{wt} \%)_{\mathrm{H}_{2}}$ only holds when the storage vessel is not considered. Commercial hydrogen storage vessels reach specific energies of $1-6(\mathrm{wt} \%)_{\mathrm{H}_{2}}$, meaning that a filled $100 \mathrm{~kg}$ storage vessel contains $1-6 \mathrm{~kg}$ of hydrogen. ${ }^{59}$

6.2. Process Conditions. The thermodynamics of iron redox cycling through eq 3 are independent of pressure, and the kinetics activity is reasonable over a wide pressure range. ${ }^{19,20}$ The temperature is a more critical process condition, influencing thermodynamics, kinetics, and cycling stability. The thermodynamic model indicates that oxidation should be performed in the temperature range $T=$ $100-500{ }^{\circ} \mathrm{C}$. Temperatures above $500{ }^{\circ} \mathrm{C}$ would increase $\beta$ and potentially decrease cycling stability. For reduction, temperatures above $400{ }^{\circ} \mathrm{C}$ were more favorable for a low energy demand. Choosing the ideal temperature for a specific application would be a trade-off between energy demand, kinetics, cycling stability, and reactor complexity. The process conditions are the same for iron and iron-based pellets. The process conditions for the other hydrogen storage technologies are taken from the literature. ${ }^{5}$

The results are presented in Table 3. Most of the reviewed storage technologies require temperatures from room temperature up to 300 ${ }^{\circ} \mathrm{C}$, while the iron chemical looping processes will likely require temperatures of $400-550{ }^{\circ} \mathrm{C}$. These relatively higher temperatures could be a considerable drawback to hydrogen storage via this route. One potential benefit of the iron storage route is that the thermodynamic limits of the storage and release reactions are independent of pressure. This may allow the pressure to be adjusted to suit the application. Lower pressures can be cheaper in some applications, avoiding the need for expensive pressure vessels. All of the other technologies require elevated pressures in the storage process.
6.3. Energy Demand. In section 3, the relative energy demand for iron-based hydrogen storage was estimated to be $\beta_{\text {iron }} \approx 27 \%$ but will depend on the exact process conditions. The energy demands for other hydrogen storage methods are taken from the literature. ${ }^{5}$ The energy demand for compressed hydrogen storage was calculated on the basis of an expected isothermal compression efficiency of $70 \%{ }^{59}$ and starting pressures from 5 to 15 bar. The full calculation can be found in the SI.

An overview of the energy demands for the different hydrogen storage technologies is shown in Figure 7. The figure distinguishes between heat and electricity needed during the hydrogen storage process and heat needed during the hydrogen release process. Additionally, $\beta(\%)$ are multiplied by $100 \mathrm{MWh}$ and shown in perspective to the total energy input required for delivering green hydrogen through electrolysis plus storage. An electrolysis efficiency of $68 \%$ is assumed in line with expectations of the International Energy Agency. ${ }^{4}$ Most of the reviewed storage technologies have relative energy demands of around 20-25\%. The most notable exception is compressed hydrogen storage, with energy demands under $10 \%$. Intermetallic hydrides also have a relatively low energy demand of ca. $14 \%$. Unlike many of the chemical storage options, iron requires most of its energy in the form of heat, which offers more flexibility in the source of the energy. Furthermore, the majority of the heat is required during the storage process, which could be a considerable benefit as energy would likely be more readily available during the storage step.

6.4. Material Cost. We also use the cost of the storage material as a performance indicator for the hydrogen storage technologies which utilize a cyclic chemical process, i.e., the chemical hydrides, LOHCs, and the metal oxide process. This should not be considered a direct measure of the capital investment cost as other system components such as pumps and reactor/storage vessels are neglected. Only the raw material cost is considered, excluding any following material preparation processes. Those processes can add up to $100 \%$ of the cost in some cases. ${ }^{5}$ Still, it is a valuable performance indicator as a high material cost could rule out a storage option as too expensive, particularly for the case of large-scale, long-term storage. ${ }^{12}$ The results 
are presented in Table 3. Iron has a very low material cost compared to most metal hydrides and is similar in material cost to LOHCs.

\section{CONCLUSIONS AND OUTLOOK}

The hydrogen storage densities of this technology are considerably lower than those of some alternatives, and the suggested process temperatures are also relatively high, making iron an unlikely choice for applications requiring a high storage density or with constraints on process conditions, such as mobile applications. On the positive side, iron is cheap, abundant, nontoxic, and relatively easy to store, and the calculated energy demand of hydrogen storage using iron is comparable to that of other chemical storage methods. It also has the advantage of requiring thermal energy rather than electrical power, with the majority of the heat required during the storage step. The storage process could be configured with a packed bed of iron oxide pellets acting simultaneously as the storage vessel and reactor. The thermodynamics of the redox reactions indicate the possibility of near ambient pressure operation, avoiding the need for high-pressure components. These properties could well make this process a suitable option for large-scale hydrogen storage over long time periods.

This storage technology has received little attention to date and there are a number of unknowns with regard to its potential for application. A dedicated study of the kinetics and cycle stability of iron-based pellets/granules at the process conditions relevant for hydrogen storage could be used to identify suitable morphologies and support materials, as well as the practical limitations of the process. This could further guide both reactor and process design and allow for a more accurate assessment of the performance of this hydrogen storage process.

\section{ASSOCIATED CONTENT}

\section{SI Supporting Information}

The Supporting Information is available free of charge at https://pubs.acs.org/doi/10.1021/acs.energyfuels.1c02615.

Complete description of the thermodynamic equilibrium calculations, full description of the thermodynamic model of the storage process, information on the different cases used for the hydrogen storage densities of iron, details on material costs, and calculation of energy demand for hydrogen compression (PDF)

\section{AUTHOR INFORMATION}

\section{Corresponding Author}

B. Bulfin - Department of Mechanical and Process Engineering, ETH Zürich, 8092 Zürich, Switzerland; ○ orcid.org/0000-0001-9361-0075; Email: bulfinb@ ethz.ch

\section{Authors}

L. Brinkman - Department of Mechanical and Process Engineering, ETH Zürich, 8092 Zürich, Switzerland

A. Steinfeld - Department of Mechanical and Process Engineering, ETH Zürich, 8092 Zürich, Switzerland; (1) orcid.org/0000-0001-7797-686X

Complete contact information is available at: https://pubs.acs.org/10.1021/acs.energyfuels.1c02615

\section{Notes}

The authors declare no competing financial interest.

\section{ACKNOWLEDGMENTS}

This research work was partially funded by the European Union's Horizon 2020 Research Infrastructure Programme (Project SFERA-III-Grant No. 823802).

\section{NOMENCLATURE}

$\mathrm{CLH}=$ chemical looping hydrogen production

$\mathrm{LHV}=$ lower heating value

LOHC = liquid organic hydrogen carrier

$p=$ pressure (bar)

$p_{i}=$ partial pressure of species $i$ (bar)

$p_{\mathrm{H}_{2} \mathrm{O}}^{\text {sat }}=$ water vapor saturation pressure (bar)

$\mathrm{SI}=$ Supporting Information

$T=$ temperature $(\mathrm{K})$

$T_{\text {red }}=$ temperature of the reduction reaction $(\mathrm{K})$

$T_{\mathrm{ox}}=$ temperature of the oxidation reaction $(\mathrm{K})$

wrt $=$ with respect to

$x_{i}=$ mole fraction of species $i$

$Q=$ quantity of heat $\left(\mathrm{J} \mathrm{mol}_{\mathrm{H}_{2}}{ }^{-1}\right)$

$\beta=$ relative energy demand, $\frac{Q}{\mathrm{LHV}_{\mathrm{H}_{2}}}$

$\Delta_{\mathrm{r}} H=$ enthalpy change of reaction $\left(\mathrm{J} \mathrm{mol}^{-1}\right)$

$\Delta_{\mathrm{r}} G=$ Gibbs free energy change of reaction $\left(\mathrm{J} \mathrm{mol}^{-1}\right)$

$\eta_{Q}=$ heat recovery efficiency/effectiveness

$t_{1 / 2}=$ half-time of a reaction $\left(\mathrm{min}^{-1}\right)$

\section{REFERENCES}

(1) Taibi, E.; Miranda, R.; Vanhoudt, W.; Winkel, T.; Lanoix, J.-C.; Barth, F. Hydrogen from renewable power: Technology outlook for the energy transition; International Renewable Energy Agency (IRENA), 2018.

(2) Hydrogen Council. Path to hydrogen competitiveness: A cost perspective; Hydrogen Council, 2020.

(3) Caglayan, D. G.; Weber, N.; Heinrichs, H. U.; Linßen, J.; Robinius, M.; Kukla, P. A.; Stolten, D. Technical potential of salt caverns for hydrogen storage in Europe. Int. J. Hydrogen Energy 2020, $45,6793-6805$.

(4) Internation Energy Agency (IEA). The Future of Hydrogen: Seizing Today's Opportunities, Report Prepared for the G20, Japan; IEA: Paris, 2019.

(5) Andersson, J.; Grönkvist, S. Large-scale storage of hydrogen. Int. J. Hydrogen Energy 2019, 44, 11901-11919.

(6) Thaler, M.; Hacker, V. Storage and separation of hydrogen with the metal steam process. Int. J. Hydrogen Energy 2012, 37, 28002806.

(7) Bergthorson, J. M. Recyclable metal fuels for clean and compact zero-carbon power. Prog. Energy Combust. Sci. 2018, 68, 169-196.

(8) Lammer, M.; Hacker, V. Current Trends and Future Developments on (Bio-) Membranes; Elsevier, 2020; pp 225-240. DOI: 10.1016/ B978-0-12-817384-8.00010-8

(9) Otsuka, K.; Kaburagi, T.; Yamada, C.; Takenaka, S. Chemical storage of hydrogen by modified iron oxides. J. Power Sources 2003, 122, 111-121.

(10) Otsuka, K.; Yamada, C.; Kaburagi, T.; Takenaka, S. Hydrogen storage and production by redox of iron oxide for polymer electrolyte fuel cell vehicles. Int. J. Hydrogen Energy 2003, 28, 335-342.

(11) Rivard, E.; Trudeau, M.; Zaghib, K. Hydrogen storage for mobility: a review. Materials 2019, 12, 1973.

(12) Ozaki, M.; Tomura, S.; Ohmura, R.; Mori, Y. H. Comparative study of large-scale hydrogen storage technologies: Is hydrate-based storage at advantage over existing technologies? Int. J. Hydrogen Energy 2014, 39, 3327-3341.

(13) Dirven, L.; Deen, N. G.; Golombok, M. Dense energy carrier assessment of four combustible metal powders. Sustainable Energy Technologies and Assessments 2018, 30, 52-58. 
(14) Steinfeld, A.; Kuhn, P.; Reller, A.; Palumbo, R.; Murray, J.; Tamaura, Y. Solar-processed metals as clean energy carriers and water-splitters. Int. J. Hydrogen Energy 1998, 23, 767-774.

(15) Preuster, P.; Alekseev, A.; Wasserscheid, P. Hydrogen Storage Technologies for Future Energy Systems. Annu. Rev. Chem. Biomol. Eng. 2017, 8, 445-471.

(16) Spreitzer, D.; Schenk, J. Reduction of Iron Oxides with Hydrogen-A Review. Steel Res. Int. 2019, 90, 1900108.

(17) Vogl, V.; Åhman, M.; Nilsson, L. J. Assessment of hydrogen direct reduction for fossil-free steelmaking. J. Cleaner Prod. 2018, 203, $736-745$.

(18) Pei, M.; Petäjäniemi, M.; Regnell, A.; Wijk, O. Toward a Fossil Free Future with HYBRIT: Development of Iron and Steelmaking Technology in Sweden and Finland. Metals 2020, 10, 972.

(19) Voitic, G.; Hacker, V. Recent advancements in chemical looping water splitting for the production of hydrogen. RSC Adv. 2016, 6, 98267-98296.

(20) Luo, M.; Yi, Y.; Wang, S.; Wang, Z.; Du, M.; Pan, J.; Wang, Q. Review of hydrogen production using chemical-looping technology. Renewable Sustainable Energy Rev. 2018, 81, 3186-3214.

(21) Smestad, G. P.; Steinfeld, A. photochemical and thermochemical production of solar fuels from $\mathrm{H} 2 \mathrm{O}$ and $\mathrm{CO} 2$ using metal oxide catalysts. Ind. Eng. Chem. Res. 2012, 51, 11828-11840.

(22) Loutzenhiser, P. G.; Meier, A.; Steinfeld, A. Review of the twostep $\mathrm{H} 2 \mathrm{O} / \mathrm{CO} 2$-splitting solar thermochemical cycle based on $\mathrm{Zn}$ / $\mathrm{ZnO}$ redox reactions. Materials 2010, 3, 4922-4938.

(23) Steinfeld, A.; Sanders, S.; Palumbo, R. Design aspects of solar thermochemical engineering-a case study: two-step water-splitting cycle using the $\mathrm{Fe} 3 \mathrm{O} 4 / \mathrm{FeO}$ redox system. Sol. Energy 1999, 65, 4353.

(24) Murugan, A.; Thursfield, A.; Metcalfe, I. A chemical looping process for hydrogen production using iron-containing perovskites. Energy Environ. Sci. 2011, 4, 4639-4649.

(25) Zhao, Z.; Uddi, M.; Tsvetkov, N.; Yildiz, B.; Ghoniem, A. F. Redox kinetics study of fuel reduced ceria for chemical-looping water splitting. J. Phys. Chem. C 2016, 120, 16271-16289.

(26) Bulfin, B.; Vieten, J.; Agrafiotis, C.; Roeb, M.; Sattler, C. Applications and limitations of two step metal oxide thermochemical redox cycles; a review. J. Mater. Chem. A 2017, 5, 18951-18966

(27) Zacharias, R.; Bock, S.; Hacker, V. The impact of manufacturing methods on the performance of pelletized, ironbased oxygen carriers for fixed bed chemical looping hydrogen in long term operation. Fuel Process. Technol. 2020, 208, 106487.

(28) Chung, C.; Qin, L.; Shah, V.; Fan, L. S. Chemically and physically robust, commercially-viable iron-based composite oxygen carriers sustainable over 3000 redox cycles at high temperatures for chemical looping applications. Energy Environ. Sci. 2017, 10, 23182323.

(29) Requies, J.; Güemez, M.; Perez Gil, S.; Barrio, V.; Cambra, J.; Izquierdo, U.; Arias, P. Natural and synthetic iron oxides for hydrogen storage and purification. J. Mater. Sci. 2013, 48, 4813-4822.

(30) Bale, C. W.; et al. FactSage thermochemical software and databases, 2010-2016. CALPHAD: Comput. Coupling Phase Diagrams Thermochem. 2016, 54, 35-53.

(31) Kearney Energy Transition Institute. Hydrogen applications and business models: Going blue and green?. Kearney, 2020.

(32) Michiels, K.; Spooren, J.; Meynen, V. Production of hydrogen gas from water by the oxidation of metallic iron under mild hydrothermal conditions, assisted by in situ formed carbonate ions. Fuel 2015, 160, 205-216.

(33) Tsai, Y. C.; Liu, L. H.; Chen, D. H. Hydrothermal generation of compressed hydrogen gas by iron powders. RSC Adv. 2016, 6, 89308934.

(34) Chen, K. F.; Li, S.; Zhang, W. X. Renewable hydrogen generation by bimetallic zero valent iron nanoparticles. Chem. Eng. J. 2011, 170, 562-567.

(35) Goodwin, D. G.; Speth, R. L.; Moffat, H. K.; Weber, B. W. Cantera: An Object-oriented Software Toolkit for Chemical Kinetics,
Thermodynamics, and Transport Processes, 2018; https://www.cantera. org.

(36) Hauch, A.; Küngas, R.; Blennow, P.; Hansen, A. B.; Hansen, J. B.; Mathiesen, B. V.; Mogensen, M. B. Recent advances in solid oxide cell technology for electrolysis. Science 2020, 370, eaba6118.

(37) Maag, G.; Zanganeh, G.; Steinfeld, A. Solar thermal cracking of methane in a particle-flow reactor for the co-production of hydrogen and carbon. Int. J. Hydrogen Energy 2009, 34, 7676-7685.

(38) Upham, D. C.; Agarwal, V.; Khechfe, A.; Snodgrass, Z. R.; Gordon, M. J.; Metiu, H.; McFarland, E. W. Catalytic molten metals for the direct conversion of methane to hydrogen and separable carbon. Science 2017, 358, 917-921.

(39) Agrafiotis, C.; von Storch, H.; Roeb, M.; Sattler, C. Solar thermal reforming of methane feedstocks for hydrogen and syngas production-a review. Renewable Sustainable Energy Rev. 2014, 29, 656-682.

(40) Romero, M.; Steinfeld, A. Concentrating solar thermal power and thermochemical fuels. Energy Environ. Sci. 2012, 5, 9234-9245.

(41) Bleeker, M. F. Pure hydrogen from pyrolysis oil using the steam-iron process. Ph.D. thesis, University of Twente, Enschede, The Netherlands, 2009.

(42) Dueso, C.; Ortiz, M.; Abad, A.; García-Labiano, F.; De Diego, L. F.; Gayán, P.; Adánez, J. Reduction and oxidation kinetics of nickelbased oxygen-carriers for chemical-looping combustion and chemicallooping reforming. Chem. Eng. J. 2012, 188, 142-154.

(43) Pineau, A.; Kanari, N.; Gaballah, I. Kinetics of reduction of iron oxides by H2. Part II. Low temperature reduction of magnetite. Thermochim. Acta 2007, 456, 75-88.

(44) Teplov, O. A. Kinetics of the low-temperature hydrogen reduction of magnetite concentrates. Russian Metallurgy (Engl. Transl.) 2012, $2012,8-21$.

(45) Lorente, E.; Pen, J. A.; Herguido, J. Ã. Kinetic study of the redox process for separating and storing hydrogen: Oxidation stage and ageing of solid. Int. J. Hydrogen Energy 2008, 33, 615-626.

(46) Wang, H.; Wang, G.; Wang, X.; Bai, J. Hydrogen Production by Redox of Cation-Modified Iron Oxide. J. Phys. Chem. C 2008, 112, 5679-5688.

(47) Wang, H.; Liu, X.; Wen, F. Hydrogen production by the redox of iron oxide prepared by hydrothermal synthesis. Int. J. Hydrogen Energy 2012, 37, 977-983.

(48) Wen, F.; Wang, H.; Tang, Z. Kinetic study of the redox process of iron oxide for hydrogen production at oxidation step. Thermochim. Acta 2011, 520, 55-60.

(49) Liu, L. H.; Tsai, Y. C.; Chen, D. H. Catalyst-enhanced hydrothermal generation of highly pure compressed hydrogen gas from iron micro-powders. RSC Adv. 2016, 6, 86938-86942.

(50) Michiels, K.; Haesen, A.; Meynen, V.; Spooren, J. Applicability of fine industrial metallic iron-rich waste powders for hydrothermal production of hydrogen gas: The influence of non-ferrous contaminants. J. Cleaner Prod. 2018, 195, 674-686.

(51) Brunet, F. Hydrothermal Production of $\mathrm{H}_{2}$ and Magnetite From Steel Slags: A Geo-Inspired Approach Based on Olivine Serpentinization. Front. Earth Sci. 2019, 7, 17.

(52) Eba, H.; Takahashi, M.; Sakurai, K. Progress of hydrogen gas generation by reaction between iron and steel powder and carbonate water in the temperature range near room temperature. Int. J. Hydrogen Energy 2020, 45, 13832-13840.

(53) Wang, Y.; Jin, F.; Zeng, X.; Yao, G.; Jing, Z. A novel method for producing hydrogen from water with $\mathrm{Fe}$ enhanced by HS- under mild hydrothermal conditions. Int. J. Hydrogen Energy 2013, 38, 760-768.

(54) Yu, Z.; Yang, Y.; Yang, S.; Zhang, Q.; Zhao, J.; Fang, Y.; Hao, X.; Guan, G. Iron-based oxygen carriers in chemical looping conversions: A review. Carbon Resources Conversion 2019, 2, 23-34.

(55) Muwanguzi, A. J. B.; Karasev, A. V.; Byaruhanga, J. K.; Jönsson, P. G. Characterization of Chemical Composition and Microstructure of Natural Iron Ore from Muko Deposits. ISRN Mater. Sci. 2012, 2012, 174803.

(56) Hacker, V.; Malli, K.; Zacharias, R.; Bock, S.Institute of Chemical Engineering and Environmental Technology. HyStORM- 
Hydrogen Storage via Oxidation and Reduction of Metals, Graz University of Technology (TU Graz), 2019; https://graz.pure. elsevier.com/en/projects/hystorm-hydrogen-storage-via-oxidationand-reduction-of-metals.

(57) Chen, J.; Yu, L.; Sun, J.; Li, Y.; Xue, W. Synthesis of hercynite by reaction sintering. J. Eur. Ceram. Soc. 2011, 31, 259-263.

(58) Kidambi, P. R.; Cleeton, J. P.; Scott, S. A.; Dennis, J. S.; Bohn, C. D. Interaction of iron oxide with alumina in a composite oxygen carrier during the production of hydrogen by chemical looping. Energy Fuels 2012, 26, 603-617.

(59) Sdanghi, G.; Maranzana, G.; Celzard, A.; Fierro, V. Review of the current technologies and performances of hydrogen compression for stationary and automotive applications. Renewable Sustainable Energy Rev. 2019, 102, 150-170. 